\title{
La población de la Misión de Santa Rosa de Lima (Paraguay)
}

\author{
Robert H. Jackson *
}

\section{Recibido: 10 de abril de 2015}

\section{Evaluado: 28 de abril de 2015}

El establecimiento de reducciones en las fronteras de la América española, entre los siglos XVI al siglo XVIII, dio lugar a notables cambios, que en algunos casos alcanzaron el colapso demográfico. El proceso de congregar las poblaciones nativas y vivir en comunidades misioneras nucleadas, facilitó la evangelización y la incorporación a un sistema colonial que explotaba la mano de obra nativa y el pago de tributos a la corona. Además reunió a las poblaciones en las redes comerciales más grandes que también facilitaron la propagación del contagio de epidemias letales que a menudo alcanzaban niveles catastróficos y en muchos casos el colapso demográfico. Otras poblaciones resultaron ser resistentes y se recuperaron de los efectos de las epidemias y otros factores que contribuyeron a elevar las tasas de mortalidad.

Las misiones jesuíticas de Paraguay proporcionan un ejemplo de los procesos de cambio demográfico, siendo el tema de este artículo. Estos pueblos estaban vinculados a otras comunidades más grandes de la región, y al transporte fluvial que también facilitaron la propagación del contagio. Por otra parte, los jesuitas organizaron compañías de la milicia en las misiones que participaron en el largo conflicto entre España y Portugal para el control de la frontera disputada del Río de la Plata. El movimiento de los ejércitos también facilitó la propagación del contagio, interrumpiendo la producción de alimentos básicos, ya que miles de hombres fueron a las campañas militares. La política social de los jesuitas en las misiones también contribuyó a la propagación del contagio. Ellos crearon comunidades nativas nucleadas en las misiones, y la vivienda nativa generalmente consistía en hileras de edificios situados cerca uno del otro con varios compartimientos. Los guaraníes vivían codo con codo en esta disposición habitacional en las condiciones ideales para la transmisión de las enfermedades contagiosas como la viruela y el sarampión. Por último, las misiones de Paraguay en su esplendor se encontraban entre las más pobladas de las ubicadas en los márgenes de la América española, y proporcionar ejemplos de la mortalidad epidémica que se acercaron a niveles como postulados para los primeros brotes en el

\footnotetext{
* Investigador independiente, Ciudad de México.
} 
siglo XVI, después del contacto sostenido entre el Antiguo y el Nuevo Mundos. Hay casos de mortalidad epidemia que llegan alcanzan el 50\% y el $60 \%$ de algunas poblaciones. Sin embargo, a diferencia de otras reducciones, las del Paraguay recuperaban después de la mortalidad epidémica catastrófica.

Los eruditos han estudiado los patrones demográficos en las misiones del Paraguay, pero la tendencia ha sido la de analizar las poblaciones de la misión en su conjunto ${ }^{1}$. El problema con este enfoque es que hubo una considerable variación en los patrones demográficos entre cada una de las reducciones, y en particular en lo que respecta a los niveles de mortalidad epidémica. No era raro que una misión experimentara una mortalidad extremadamente alta, mientras que al mismo tiempo una comunidad vecina evidenció una menor mortalidad. El enfoque global empleado por algunos no toma en cuenta esta variación. Además, se requiere un análisis de las causas de las diferencias. Mis propias contribuciones han examinado los patrones globales, sino también detalla los estudios de caso y un enfoque comparativo que ilumina los patrones demográficos ${ }^{2}$. Se puede tener una mayor comprensión de los patrones demográficos de las misiones de Paraguay a través de estudios de casos detallados y un enfoque comparativo. El estudio de caso de la misión de Santa Rosa de Lima que se presenta aquí, ofrece ideas para el proceso de la formación de estas comunidades, y de los efectos de la última epidemia catastrófica (1763-1765) que se propagaron a través de las misiones, previamente a la expulsión de los jesuitas en 1767, y que también fue relacionado con una guerra no declarada en curso entre España y Portugal.

En un estudio reciente discutí interpretaciones teóricas de las tendencias demográficas nativas tras el contacto sostenido con el Viejo Mundo y sus enfermedades, incluyendo los patrones de cambio como consecuencia de las epidemias. ${ }^{3}$ Este artículo examina un caso de estudio de los patrones demográficos y de la mortalidad epidémica. Se centran en la población de la misión de Santa Rosa de Lima. Muestra, por ejemplo, cómo se recuperó una población discreta después de brotes epidémicos catastróficos.

Estudios demográficos detallados de las poblaciones, se basan primeramente en varias fuentes que incluyen registros de bautismos, matrimonios y entierros, así como los censos elaborados con diferentes niveles de detalle. Sólo pequeños fragmentos de registros sacramentales sobrevivieron de las misiones del Paraguay, pero hay uno particular que registra los bautismos para Santa Rosa en la década de 1750 y 1760. Como parte de su responsabilidad de informar a la Compañía de Jesús y a la Corona española, los jesuitas prepararon narraciones sobre las misiones conocidas como Cartas Anuas, detallados censos de tributarios ordenados por la Corona, así como los censos anuales que informaron diferentes categorías de información. La Annua Enumeratio Reductionum (un censo anual) divide las poblaciones en las categorías de edad y sexo, así como el estado civil. Por otro lado, también resumió el número de bautismos, matrimonios y entierros para cada misión. Dado que las misiones del Paraguay tenían poblaciones cerradas, esto es que generalmente los jesuitas no congregaron nativos nocristianos en las comunidades, las cifras sobre el número de bautismos se correspondían con el número de nacimientos. Los jesuitas no estandarizaron el formato de los censos hasta la década de 1720, y se prepararon ambos tipos. No todos los censos se han

\footnotetext{
${ }^{1}$ Ver Livi-Bacci y Maeder, 2004.

${ }^{2}$ Ver Jackson, 2004a; Jackson, 2004b; Jackson, 2007, Jackson, 2008, Jackson, 2009; Jackson, 2014.

3 Jackson, 2014.
} 
conservado, pero hay una muestra lo suficientemente grande como para reconstruir las tasas vitales y patrones demográficos ${ }^{4}$.

El análisis de los efectos de los brotes epidémicos debe tener en cuenta los diferentes factores que incluyen la estructura por edad y sexo de la población, así como el número de personas potencialmente susceptibles, que era en general, los nacidos desde el brote anterior. En promedio, una epidemia se extendió a través de las misiones de Paraguay sobre una vez por generación, o cada 20 años. Sin embargo, cada brote no afectó todas las misiones, y la mortalidad varió entre esas comunidades. Este artículo examina el brote de la viruela en Santa Rosa en 1764, en un contexto comparativo. También debe observar los patrones de mortalidad en los brotes anteriores, que tenían una relación directa con la estructura de la población de la misión, así como la mortalidad en 1764. Las epidemias generalmente sacrificaban más fuertemente a la población de los nacidos desde el brote anterior, que se definen en los censos como parvulos o sea niños menores de diez, y adultos jóvenes (edad de diez años a 20). Cualquier diferencia se explica, en parte, por estar relacionados con lo ocurrido durante los brotes anteriores.

\section{La población de Santa Rosa}

Santa Rosa fue una de las últimas misiones establecidas en Paraguay. Los jesuitas establecieron la misión en 1698 en un sitio cerca de San Ignacio Guazú, en lo que hoy es el sur de Paraguay, con nativos de origen de la región Itatín noreste de Asunción que residía en la misión de Nuestra Señora la $\mathrm{Fe}^{5}$. La población de Santa Rosa creció con fuerza en las tres primeras décadas del siglo XVIII debido a las altas tasas de natalidad, y las tasas vitales eran típicas de las poblaciones de las misiones del Paraguay con altas tasas de fecundidad y de mortalidad. Las tasas brutas de mortalidad (TBM) eran altas, pero en los años sin epidemias las tasas de nacimiento eran más altas. La tasa bruta de natalidad (TBN) fue de 82,1 por cada mil habitantes en 1702, y 74,1 en 1724. En 1702, cuatro años después del establecimiento de la misión, 2.879 nativos vivían en Santa Rosa, y este número aumentó a 6.093 en 1731. Santa Rosa era una de las misiones de Paraguay más pobladas (ver Tabla 1).

Una epidemia de viruela desatada entre 1718-1719 interrumpió el crecimiento de la población de la misión de Santa Rosa ${ }^{6}$. No hay cifras sobre los nacimientos o muertes, pero la magnitud de la disminución se pueden medir como la variación porcentual de la población entre 1717 y 1720, los dos años para los cuales existen

\footnotetext{
4 La reconstrucción de las tasas vitales de la reducción de Santa Rosa se basa en censos de manuscritos (censos anuales) del Archivo General de la Nación en Buenos Aires (AGN), el Archivo Nacional de Paraguay (ANP) en Asunción, y el Archivo General de Indias (AGI) en Sevilla, España. Para los años 1711, 1714, 1715, 1716, 1717, 1720, 1724, 1728, 1731, 1733, 1735, 1736, 1738, 1739, 1740, 1741, 1744, 1745, 1746, 1747, 1748, 1749, 1750, 1752, 1753, 1754, 1755, 1756, 1757, 1759, 1760, 1762, 1763, 1764 , 1765 y 1767 del AGN, Sala IX-7-2-1, 6-9-6, 6-9-7, 6-10-6; "Empadronamiento de las Treinta Pueblos de Misiones, por el Coronel Don Marcos de Larrazábal" 1772, AGN, Sala IX-18-8-4; los censos de 1797 a partir de la AGN, Sala IX-18-6-5; para 1798 del AGN, Sala IX-18-2-4; 1799 AGN, Sala IX-18-2-5; censos para las misiones individuales para 1801 de AGN, Sala IX-17-3-6. Censo de 1724 de la ANP. Para 1702 de Francisco Burges, SJ, No Place, Sin fecha [1705], "Francisco Burges de la Compañía de Jesús, Procurador de la Provincia de Paraguay", AGI, Charcas 381. También Santa Rosa Registro Bautisma de Santa Rosa, Santa Rosa Archivo Parroquial, Santa Rosa, Paraguay.

${ }^{5}$ Maeder 1996: 50; Page, 2015: 5-6.

${ }^{6}$ La Carta Anua de 1720 mencionó que hubo una epidemia en 1718, sin ofrecer muchos detalles.
} 
censos (ver Tabla 1). En 1717, la población de Santa Rosa fue 5.389, y se redujo a 4.230 en 1720, es decir un descenso del 21,6\%, o una tasa bruta de mortalidad (TBM) de alrededor de 210 por mil. En 1718 el obispo de Buenos Aires fray Pedro Fajardo O.SS.T, visitó las misiones y confirmó miles de guaraní. Estaba en Yapeyú a mediados del mes de junio informó que la epidemia de la viruela ya se había extendido a la misión. El prelado también comunicó que la viruela había estallado en San Tomé, San José que visitó a mediados de septiembre, Santos Cosme y Damián que también visitó a mediados de septiembre, Trinidad e Ytapúa. Fray Fajardo señaló específicamente que Santa Ana y San Luis Gonzaga estaban libres del contagio, y no reportó el contagio en Santa Rosa ${ }^{7}$. La población de Santa Rosa se recuperó y creció a 6.093 habitantes en 1731.

Una serie de epidemias se extendió a través de las misiones en los años 1733, 1735 a 1736, y nuevamente en 1738-1740. El último de los tres fue un brote de viruela. La TBM en Santa Rosa era aproximadamente 459,2 por mil habitantes en 1733 durante el primer brote, y 490,3 por mil habitantes en 1736 durante el segundo. Las muertes en 1733 se distribuyeron entre 900 adultos y 1.363 párvulos. La población de la misión se redujo en $76 \%$ entre 1731 y 1736, y era 1.671 a finales de 1736 (véase el cuadro 2).

La epidemia de viruela ubicada entre 1738 y 1740 parece haber matado a pocas personas en Santa Rosa. Los dos brotes anteriores redujeron la población, y los números comenzaron a crecer lentamente de nuevo. Entre 1736 y 1738, la población aumentó de 1.671 a 1.828, o un aumento de $9 \%$. El efecto mínimo de la viruela en la población de Santa Rosa fue un factor importante en la alta mortalidad causada por la viruela en 1764. Hubo casi treinta años entre las epidemias catastróficas. Un brote de sarampión en 1748 mató a un menor número de personas. Un total de 249 murieron en el año, o una TBM de 195,8. La situación era similar en Loreto, la otra misión que sufrió mortalidad catastrófica durante la epidemia de viruela en 1763-1765. La TBM en Loreto fue 145,0 en 1733 y 308,4 en 1736, y una disminución total en la población de $68 \%$. A raíz de la epidemia de 1736, la población de Loreto se recuperó y creció. Por ejemplo, se incrementó en un 15\% entre 1736 y 1738 . Uno de los mecanismos para el crecimiento de la población fue la formación de nuevas familias y las TBN más altas. Esto puede verse, por ejemplo, en el aumento del número de matrimonios. Efectivamente los matrimonios en Loreto sumaron 14 en 1724 y 59 en 1728. Esto aumentó a 263 en 1733. Las mujeres guaraníes también se casaron a una edad joven poco después de la pubertad, entre unos 13 o 14 años de edad ${ }^{8}$.

La población de Santa Rosa se recuperó y creció después las epidemias de la década de 1730. La TBN en 1736 era de 189,3 por mil habitantes, que fue la tasa de natalidad más alta registrada en la misión y puede haber incluido los bautismos de no cristianos que se congregaron en la misión. En 1746, la población era de 2.288, llegó a 3.056 en 1756 y 3.196 en 1760. Un fragmento de un registro bautismal existe para los años 1754 a $1763^{9}$. En diez años los jesuitas bautizaron a 1.801 niños, o un promedio de 180 por año. En este período, la población experimentó un crecimiento robusto.

\footnotetext{
${ }^{7}$ Razón de la visita que Hizo el Ilustrísimo y reverendísimo señor don Fray Pedro Fajardo, Obispo de Buenos Aires, El ano de 1718, en Pastells, 1948, 6: 172-177.

${ }^{8}$ Ver Jackson 2004a.

${ }^{9}$ Registro de bautismos de Santa Rosa, Archivo Parroquial de Santa Rosa, Paraguay.
} 


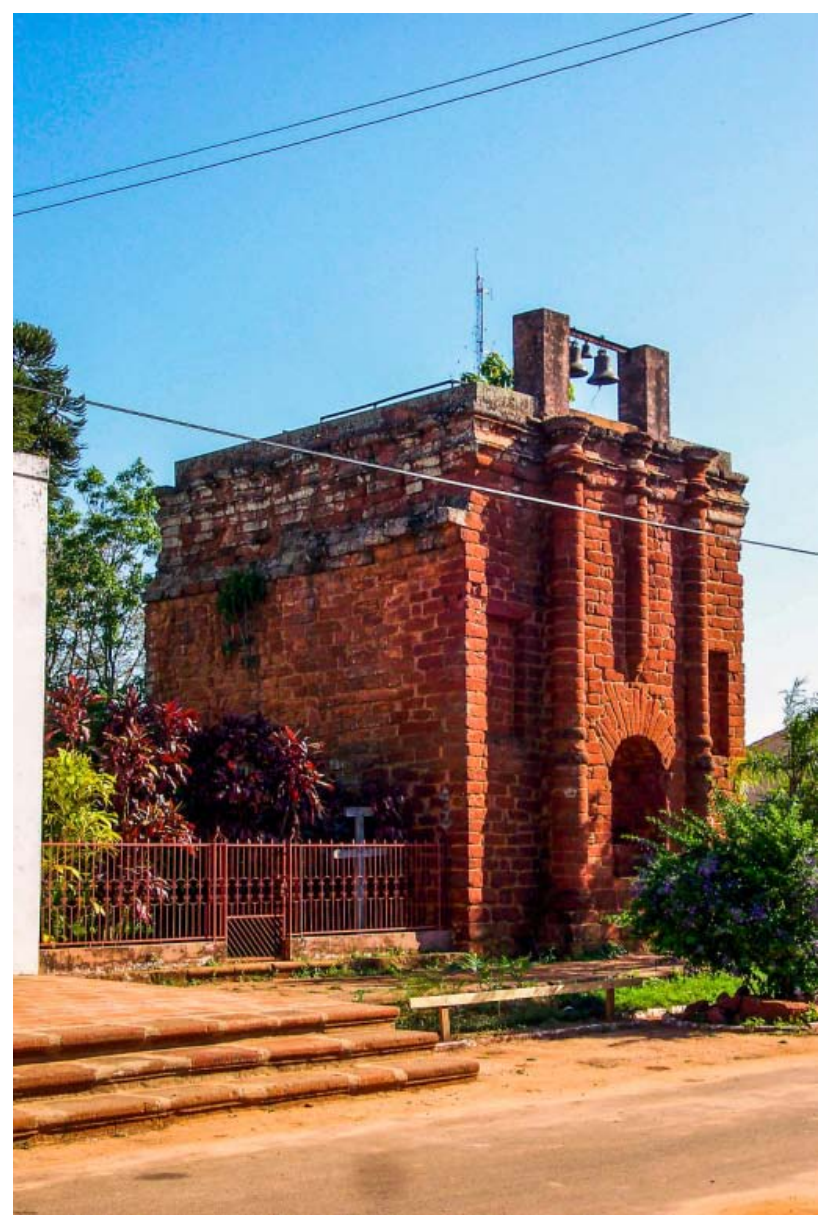

Fig. 1. La inconclusa torre campanario de la antigua iglesia de Santa Rosa

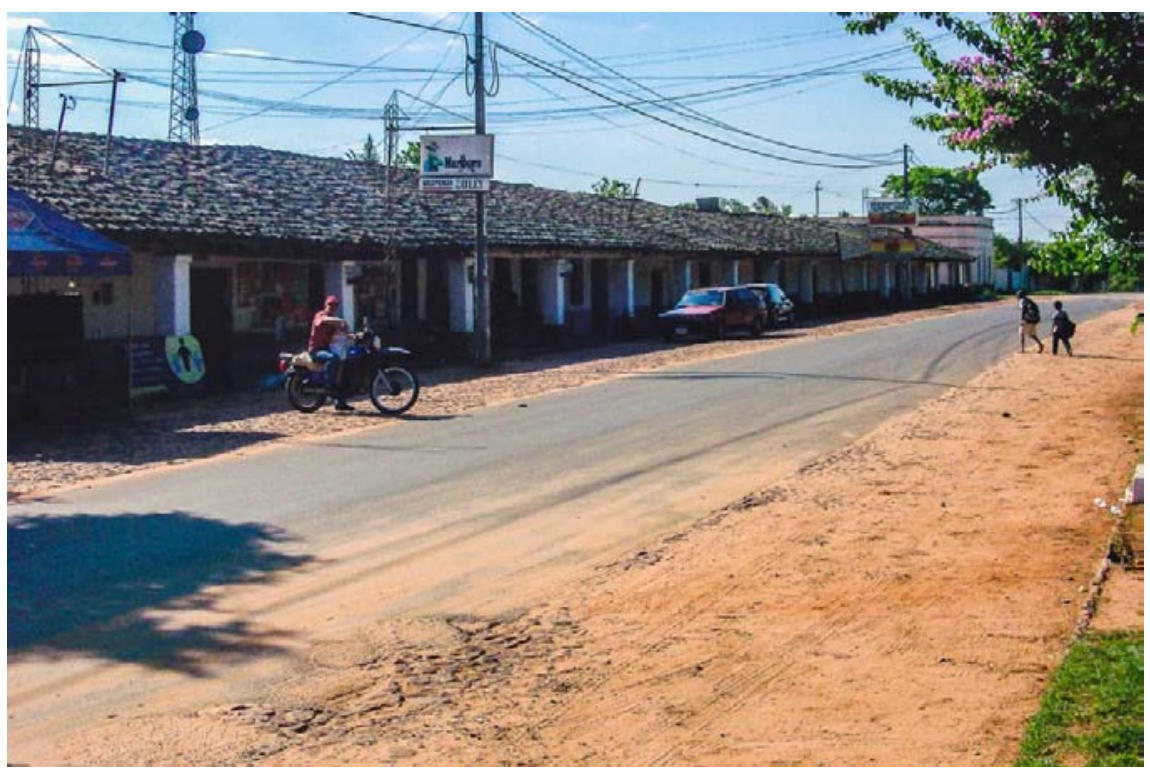

Fig. 2. Un antiguo edificio de la misión que albergaba familias neófitos. Estos vivieron codo con codo en pequeños núcleos habitacionales de largas estructuras, como ésta que contenían varios apartamentos. Este sistema de vivienda facilitó la propagación del contagio. 
En 1750, los reyes de España y Portugal firmaron el Tratado de Madrid, que intentó definir las fronteras de Brasil y los territorios españoles en América del Sur. Bajo los términos del Tratado, España cedió el territorio de las siete misiones jesuíticas situadas al este del río Uruguay a Portugal, a cambio de la Colonia de Sacramento, ubicada en la actual República de Uruguay. Una cláusula en el tratado acordó la acción militar español-portugués conjunta si los residentes guaraníes de las misiones decidieran resistir la transferencia de territorio. El gobierno español dio a los residentes guaraníes de las siete misiones la opción de trasladarse a territorio español, o permanecer bajo el dominio portugués. Los líderes guaranís de las siete misiones optaron por resistir a la transferencia. En 1755, la milicia guaraní de las siete misiones obligó a una fuerza militar española a retirarse del territorio de las misiones. Sin embargo una mayor fuerza española-portuguesa venció a la milicia guaraní en el año siguiente en la batalla de Caibaté.

En 1762, un nuevo rey español anuló unilateralmente el Tratado de Madrid, y ordenó a la reocupación del territorio al este del río Uruguay. Hubo otra década de guerra mientras que España y Portugal se disputaban la región fronteriza de Río Grande do Sul. En 1777 los dos países firmaron el Tratado de San Ildefonso que definió los límites de Brasil y el territorio español en América del Sur. Mientras que las misiones ubicadas al Este del río Uruguay se mantuvieron bajo control español hasta $1801^{10}$.

Censos de las misiones entre 1756 y 1766 documentaron la diáspora de las siete reducciones orientales y la reocupación después de 1762. El mayor número de refugiados fueron a las misiones inmediatamente al oeste del río Uruguay, y el más cercano al territorio transferido a los portugueses. En 1759, 9.133 de los refugiados vivían en siete misiones en esta área (Concepción, San Francisco Javier, San Carlos, San José, Apóstoles, Santos Mártires y Santa María la Mayor. En el momento de la reubicación los funcionarios reales creen que la transferencia de la población sería permanente. En la medida de lo posible, los jesuitas trasladaron a los guaraníes de las misiones orientales a las misiones con las cuales había lazos sociales, históricos y familiares, a fin que la transferencia estaría lo menos difícil posible para los residentes de las misiones orientales. Los jesuitas habían transferido guaraní de este distrito para establecer varias de las misiones orientales a finales del siglo XVII, y los vínculos sociales y familiares todavía existían.

Un número menor de refugiados fueron reubicados en otras misiones jesuíticas. Un total de 5.133 individuos se ubicaron en lo que hoy es el sureste de Paraguay (Trinidad, Santos Cosme y Damián, Jesús de Tavarangue, Ytapúa, Santa Rosa, Santiago y Nuestra Señora la $\mathrm{Fe}$ ). Varias de este grupo de misiones tenían poblaciones relativamente pequeñas, y podrían fácilmente absorber la afluencia de los nuevos habitantes. En 1759, por ejemplo, Santos Cosme y Damián tenía una población de 1.672. En ese momento la misión ocupó un sitio cerca de la orilla oeste del río Paraná, cerca de otras misiones (Santiago, La Fe, Santa Rosa y San Ignacio Guazú). La transferencia de refugiados de las misiones del Este pudo haber sido el factor decisivo en la determinación de trasladar Santos Cosme y Damián en 1760 a un nuevo sitio en la misma zona, al Oeste del río Paraná, pero más lejos de otras misiones a fin de evitar cualquier posible conflicto por la tierra con las misiones cercanas. En 1753, la población

\footnotetext{
${ }^{10}$ Para un resumen de la sublevación guarani ver Ganson, 2003: 87-117. Para la reubicación de las poblaciones de las siete reduciones orientales ver Jackson, 2008: Tabla 1, 405-406.
} 
de las cuatro misiones vecinas ascendió a $13.495^{11}$. En 1765, tras la conclusión formal de la guerra, 2.207 refugiados aun residían en las tres misiones, y 2.072 en el año siguiente, cuando la mayoría de los refugiados ya había regresado a las misiones, al Este del río Uruguay.

Dos misiones ubicadas en Corrientes, en la orilla Oeste del río Uruguay, acogieron a 3.782 refugiados en 1759. La mayoría (3.721) residía en Santo Tomé, ubicado al otro lado del río de San Francisco de Borja, una de las misiones orientales. Los residentes guaraníes de esta última tenían vínculos históricos, sociales, familiares con los habitantes de Santo Tomé. Además, a diferencia de las misiones, Santo Tomé se encuentra a cierta distancia de las misiones vecinas y por lo tanto no había posibilidad de conflictos por la tierra. En 1759, la población de Santo Tomé alcanzó los 3.277 habitantes, y en ese año hubo 3.721 guaraníes de San Francisco de Borja en la misión que los funcionarios españoles habían trasladado a corta distancia a través del río Uruguay. Algunos guaraníes permanecieron en el territorio que controló Portugal en virtud de los términos del Tratado. En 1759, 3.836 guaraníes vivían en estancias de la antigua tierra de la reducción, ahora bajo jurisdicción portuguesa. Estos refugiados al parecer fueron trasladados más tarde a las misiones del Oeste del río Uruguay.

Tras la derogación española del Tratado de Madrid, la población guaraní de las siete misiones orientales regresó a sus comunidades. Sin embargo, la reocupación de las mismas llevó varios años, y fue un proceso gradual de reasentamiento con la población de las misiones ubicadas más cerca de los asentamientos portugueses (San Juan Bautista, Santo Ángel Custodio, San Luis Gonzaga) vueltas a ocupar a un ritmo más lento. Tras el cese de las hostilidades durante la Guerra de los Siete Años, España y Portugal se encontraron en una guerra no declarada por el control de Rio Grande do Sul, que duró una década. En 1766, 3.187 refugiados procedentes de dos misiones orientales aun residían en otras misiones, y estaban allí cuando la propagación de la viruela a través de las misiones.

En 1763, un ejército español utilizó las misiones de Paraguay como base de operaciones para una invasión de asentamientos portugueses en Rio Grande do Sul. Los soldados llevaron la viruela en el distrito reduccional. Una grave epidemia se extendió a través de las misiones a fines del año 1763, matando al menos a 12.029 guaraníes en los dos últimos años del brote como se informó en los censos de 1764 y 1765 que resumían las muertes a causa de viruela. El contagio primero estalló en la misión de Santos Cosme y Damián, donde los jesuitas registraron 331 entierros en 1763, o una TBM de 215,6 por mil habitantes. El contagio se había corrido su curso a principios de 1764, como el número de muertes en la misión se redujo a 144 en 1764 y 173 en el año siguiente $^{12}$. La próxima estalló en Santa María la Mayor a finales de 1763, y continuó hasta el año siguiente. En 1763, 316 guaraníes murieron allí, y otros 712 en 1764. La TBN llegó a 123,7 en el primer año y 354,8 en el segundo. A partir de estas dos misiones de la viruela se extendió a casi todos los establecimientos de Paraguay.

\footnotetext{
${ }^{11}$ Jackson, 2014: 122-129.

${ }^{12}$ Ibid. 2008: 419.
} 


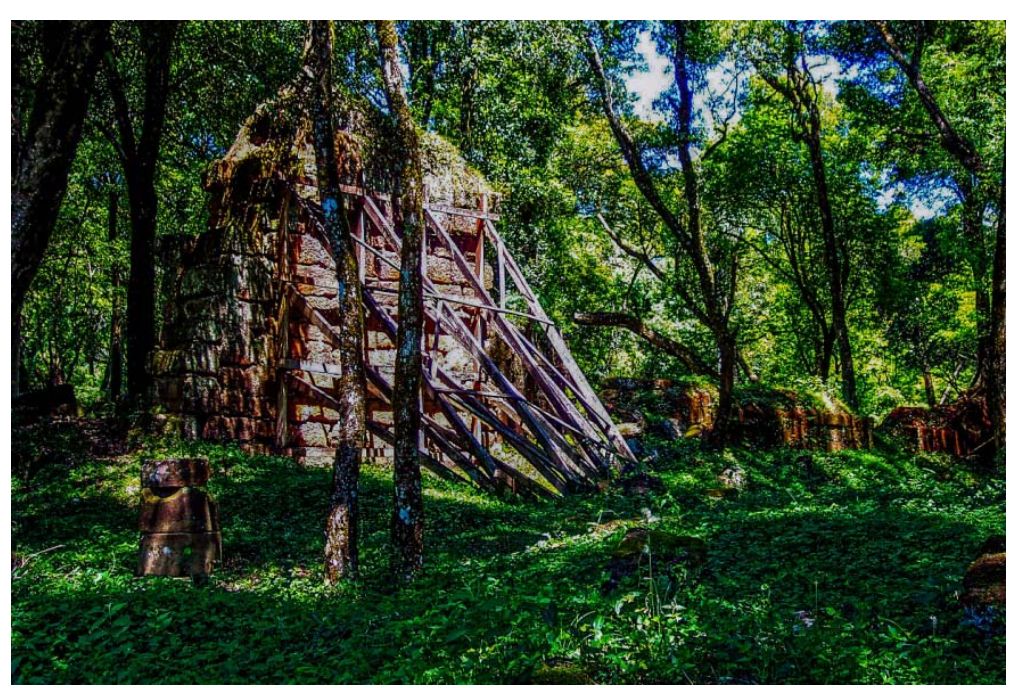

Fig. 3. Las ruinas de la iglesia de la misión de Loreto.

La Población de Santa Rosa, 1702-1893

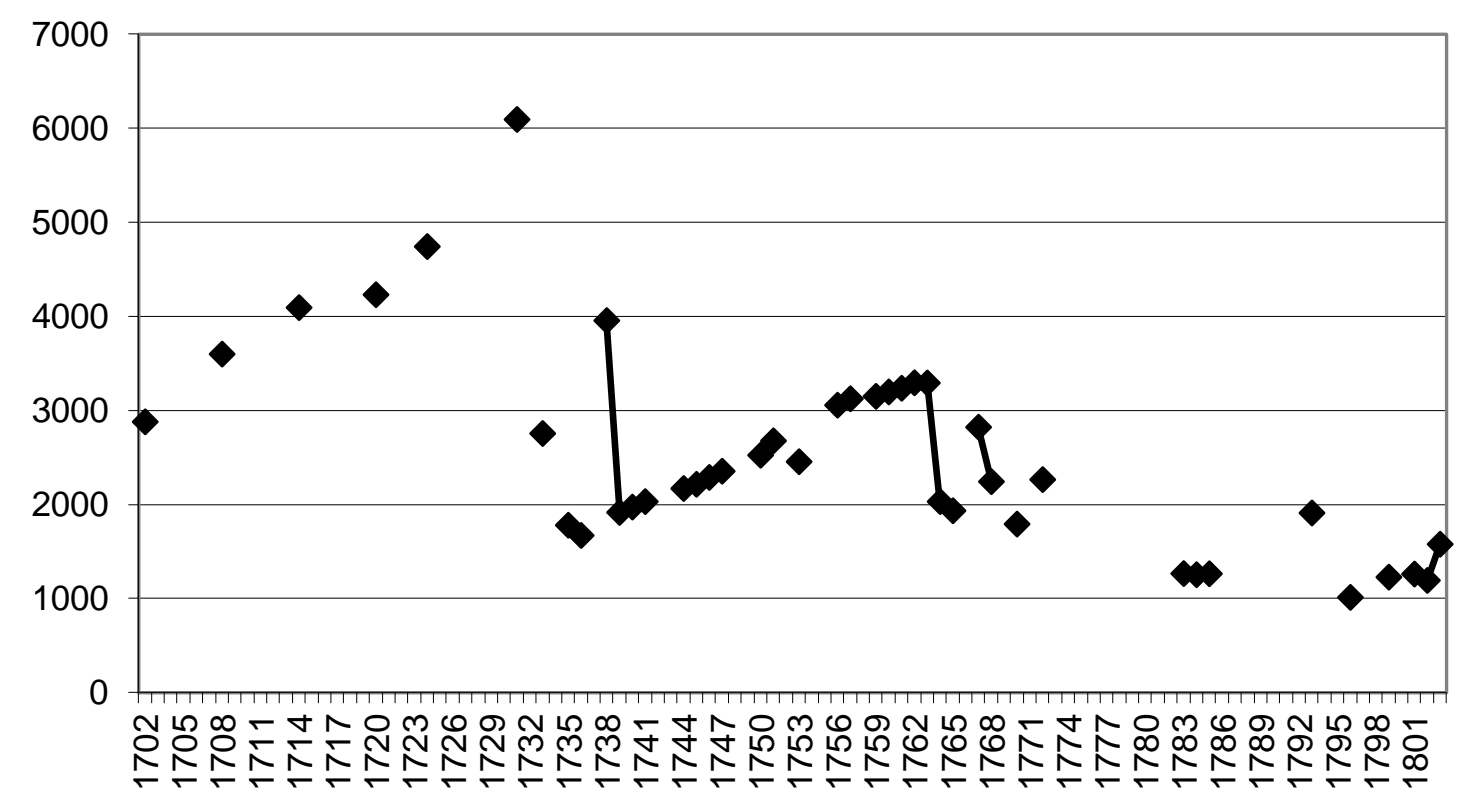

La viruela se extendió a Santa Rosa a finales de 1763, y se volvió especialmente letal en 1764. La TBM fue 69,2, frente a un TBN de 57,1 en 1763, y los entierros totalizaron 228 desde 177 registrados en 1762. En el año siguiente 1.614 nativos murieron divididos entre 1.199 adultos y 415 párvulos. Los 1764 y 1765 los censos generales también registraron el número de muertes atribuidas a la viruela, y el contagio se cobro la vida de 1.596 en Santa Rosa, o el 98,9\% de todas las muertes en el año. La TBM alcanzó 490,3, que fue una de las tasas más altas registradas en las misiones de Paraguay. La población disminuyó a 1.934 a finales de 1765. La viruela se extendió a la misión de Loreto en 1765, y mató a 1.833. Entierros totales en Loreto en 1765 alcanzaron a 2.306, dividido entre 198 adultos y 2.108 niños pequeños, y una TBM de 
464,6 por mil habitantes. La población de Loreto se redujo de 4.937 en 1764 a 2.395 en $1765^{13}$.

Las poblaciones de Santa Rosa y Loreto eran especialmente vulnerables a la viruela a principios de los años 1760, como consecuencia de los patrones de mortalidad durante las epidemias en la década de 1730. Las dos primeras epidemias mataron muchas personas en Santa Rosa y Loreto, pero pocos murieron de viruela durante el brote de 1738-1740. El número de los guaranís potencialmente susceptibles fue alto en ambas misiones a principios de los años 1760. La población de Santa Rosa se recuperó lentamente después de la devastadora epidemia de viruela, y siguió creciendo en los años inmediatamente después de la expulsión de los jesuitas y su sustitución por los franciscanos. Dos factores eran importantes en la recuperación de la población misionera. En primer lugar, a pesar de la mortalidad pesada de mujeres en la edad fértil, las mujeres aun constituían un gran porcentaje de la población total de la misión. La evidencia sugiere que la viruela no era un asesino igual, y las reacciones del sistema inmune de mujeres que producen una fuerte respuesta a la aparición de la infección TH2 tienden a tener mayores tasas de mortalidad de la viruela. Una respuesta más fuerte TH-2 parece exacerbar una infección de la viruela ${ }^{14}$. Como muestra la Tabla 3, el porcentaje de mujeres en la población total de Santa Rosa cayó tras la epidemia, pero no hasta el punto de causar un desequilibrio de género en la población. Lo mismo ocurrió en Loreto. El porcentaje de la población femenina se redujo de 53,6 en 1764 a 49,2 en 1765. Al mismo tiempo hubo un aumento en la formación de nuevas familias después de la epidemia, como se muestra en un aumento en el número de matrimonios (ver Tabla 4). Los jesuitas estacionados en Santa Rosa y Loreto realizaron 70 matrimonios antes de la epidemia. Esta cifra aumentó a 238 en Santa Rosa y 303 en Loreto. Esto también llevó a un aumento de las tasas de natalidad. En 1767, la población de Santa Rosa fue 2.243, y aumentó ligeramente a 2.265 en 1772.

La expulsión de los jesuitas de las misiones de Paraguay en 1768 dio lugar a un cambio radical en los patrones demográficos en Santa Rosa. Los franciscanos reemplazaron a los jesuitas y los funcionarios reales crearon una administración civil para reemplazar el sistema administrativo. En los años 1780 y 1790, la población de Santa Rosa disminuyó como consecuencia de la emigración y las epidemias. Hubo un total de 1.264 habitantes en 1785, 1.261 en 1801 y 1.193 en 1802. El censo de 1799 documentó la emigración. En ese año 1.228 nativos vivían en la misión, y otro 286 estaban ausentes. Los oficiales reales los clasificaron como "fugitivos", ya que se suponía que estaban legalmente vinculados a las misiones. De los ausentes 218 o el 76,2 \% eran hombres y jóvenes en edad de trabajar, y sólo 55 mujeres (19.2 \%) estaban ausentes $^{15}$. Muchos abandonaron la misión para encontrar trabajo en la economía regional en una etapa de expansión.

Un segundo registro bautismal fragmentario existe para los años 1806-1828, que documenta los cambios importantes en la población de Santa Rosa. Documenta una continuidad en la función social y política del cacicazgo después de la expulsión de los jesuitas. Los sacerdotes siguieron registrando el cacicazgo a que los padres pertenecían en el momento del bautismo de sus hijos. Los caciques retuvieron autoridad social y

\footnotetext{
13 Jackson, 2014: 122-129.

${ }^{14}$ Garenne y Lafon, 1998: 167-189.

15 Estado que manifiesta el número total de Almas de que se compone este Pueblo de Sta Rosa del Paraguay, y de las que se hallan prófugas..., Santa Rosa, abril 17, 1799, AGN, Sala 9-18-2-2.
} 
política, incluso cuando algunos ya no tenían tributarios o sólo un número muy reducido. Casi al mismo tiempo no nativos se establecieron en Santa Rosa. Entre 1806 y 1827, los sacerdotes de Santa Rosa bautizaron 483 niños no nativos. También bautizados 461 hijos de parejas nativos en los años 1822 a 1828, o un promedio de 66 por año ${ }^{16}$. A finales de la década de 1820 , Santa Rosa se estaba convirtiendo en una comunidad étnicamente mixta.

\section{Conclusiones}

Los patrones demográficos en las misiones de Paraguay eran distintos de los documentados para las misiones en otras fronteras de la América española, y especialmente las del norte de México. Las poblaciones asentadas en las misiones en la frontera norte de México colonial demostraron ser demográficamente frágil. A pesar de la mortalidad epidémica catastrófica que se documenta, por ejemplo, para Santa Rosa en 1764, las poblaciones de las misiones de Paraguay recuperaron y experimentaron crecimiento a través de la reproducción natural. La población de Santa Rosa no evidencia los desequilibrios de género y edad como, por ejemplo, las poblaciones de las misiones de California y Baja California que precipitaron cerca de la extinción biológica y cultural. La población de la misión de Santa Cruz en California es un ejemplo de un caso extremo de desequilibrio de género. De 1791 a 1833, los franciscanos bautizaron 1.133 niñas y mujeres en la misión. Sin embargo, en 1833, sólo 87 mujeres y niñas permanecieron en la misión, y constituían sólo el 31\% de la población total. Los niños pequeños también constituyen un pequeño porcentaje de la población ${ }^{17}$.

La política jesuita contribuyó a la creación de condiciones que facilitaron la propagación del contagio, y la mortalidad catastrófica epidémica. Una de estas fue el plan urbanístico aprobado en las misiones de Paraguay, de viviendas en hileras de edificios, cada uno con múltiples apartamentos. Los guaraníes vivían codo con codo en las comunidades de misión, y el contagio se extendió por contacto de persona a persona entre los miles que vivían en las proximidades de uno al otro. La congregación o el reasentamiento de las poblaciones nativas en las comunidades espacialmente compactos fue un factor importante que contribuyo a la evolución demográfica. Otro ejemplo es la formación de comunidades de misión en la región de la Sierra Gorda de México en la década de 1740. Los Pames habían vivido previamente en un patrón de asentamiento disperso en una zona montañosa accidentada, un patrón que amortiguada los efectos de las epidemias. Entre 1744 y 1746, los franciscanos se congregaron más de 7.000 Pames en cinco misiones. Las epidemias mataron a cientos de Pames y las muertes superaron a los nacimientos. Tras la secularización de las misiones en 1770, muchos de los sobrevivientes regresaron a pequeñas aldeas en las montañas, y abandonaron las misiones ubicadas en los valles, y el forzado cambio de su forma de vida ${ }^{18}$.

En las tumultuosas primeras décadas del siglo XIX, ejércitos marcharon a través de la región más grande de Río de la Plata, y destruyeron un número importante de las antiguas misiones y dispersaron las poblaciones guaraníes. Santa Rosa se salvó de la destrucción por los ejércitos merodeadores, y continuó funcionando como una comunidad multiétnica. Un informe de 1804 describe la iglesia de la misión y de la

\footnotetext{
${ }^{16}$ Registro de bautismos de Santa Rosa.

17 Jackson, 1994: 113.

${ }^{18}$ Jackson, 2013: 46-91.
} 
economía del guaraní en Santa Rosa. El informe describe la iglesia como "suntuoso con tres naves y media naranja [cúpula], y es sin duda el más rico en adornos de plata y oro, una challis hecho con buen gusto de este metal [de oro] es digno de atención". La población en 1804 era de alrededor de 1.200, incluyendo 300 trabajadores ("yndios de Tarea"). Produjeron trigo y azúcar, y se cultivan unas 40.000 plantas de tabaco. La comunidad poseía 22.631 de todo tipo de ganado, incluyendo vacas, ovejas y cabras, y los caballos ${ }^{19}$. Santa Rosa era una población demográficamente viable.

Tabla 1: La Población de Santa Rosa en años seleccionados (Jackson, 2014: 88-133)

\begin{tabular}{|c|c|c|c|c|c|}
\hline Año & Población & Año & Población & Año & Población \\
\hline 1702 & 2,879 & 1746 & 2,288 & 1772 & 2,265 \\
\hline 1708 & 3,599 & 1747 & 2,354 & 1783 & 1,266 \\
\hline 1714 & 4,093 & 1748 & 2,455 & 1784 & 1,254 \\
\hline 1715 & 4,184 & 1749 & 2,524 & 1785 & 1,264 \\
\hline 1716 & 4,268 & 1750 & 2,601 & 1793 & 1,910 \\
\hline 1717 & 5,389 & 1752 & 2,780 & 1799 & 1,228 \\
\hline 1720 & 4,230 & 1753 & 2,838 & 1801 & 1,261 \\
\hline 1724 & 4,742 & 1754 & 2,921 & 1802 & 1,193 \\
\hline 1728 & 6,064 & 1755 & 3,051 & 1803 & 1,578 \\
\hline 1731 & 6,093 & 1756 & 3,056 & & \\
\hline 1733 & 2,775 & 1757 & 3,124 & & \\
\hline 1735 & 1,859 & 1759 & 3,150 & & \\
\hline 1736 & 1,671 & 1760 & 3,197 & & \\
\hline 1738 & 1,828 & 1761 & 3,236 & & \\
\hline 1739 & 1,916 & 1762 & 3,294 & & \\
\hline 1740 & 1,973 & 1763 & 3,292 & & \\
\hline 1741 & 2,031 & 1764 & 2,031 & & \\
\hline 1744 & 2,170 & 1765 & 1,934 & & \\
\hline 1745 & 2,215 & 1767 & 2,243 & & \\
\hline
\end{tabular}

Tabla 2: Tasas Vitales de Santa Rosa en años seleccionados (Registro Bautismal de Santa Rosa, Santa Rosa Archivo Parroquial de Santa Rosa, Santa Rosa, Paraguay; ver también los documentos indicados en la nota 3 a continuación).

\begin{tabular}{|l|c|c|c|c|c|c|c|}
\hline Año & Población & Familias & Bautismos & Entierros & TBN & TBM & TPF \\
\hline 1702 & 2879 & 661 & 224 & 73 & $82.1^{*}$ & $26.8^{*}$ & 4.4 \\
\hline 1724 & 4742 & 1076 & 345 & 257 & $74.1^{*}$ & $55.2^{*}$ & 4.4 \\
\hline 1728 & 6064 & 1170 & 289 & 217 & $48.2^{*}$ & $18.2^{*}$ & 5.2 \\
\hline 1733 & 2775 & 546 & 110 & 2263 & $22.3^{*}$ & $459.2^{*}$ & 5.1 \\
\hline 1736 & 1671 & 389 & 337 & 80 & 189.3 & 44.9 & 4.3 \\
\hline
\end{tabular}

${ }^{19}$ Lovay, 2013: 322-328. 
IHS. Antiguos jesuitas en Iberoamérica ISSN: 2314-3908 vol. 3 no 1

\begin{tabular}{|l|l|l|r|r|r|r|r|}
\hline 1739 & 1916 & 460 & 126 & 82 & 68.9 & 44.9 & 4.2 \\
\hline 1740 & 1973 & 486 & 146 & 94 & 76.2 & 49.1 & 4.1 \\
\hline 1741 & 2031 & 506 & 184 & 117 & 93.3 & 59.3 & 4.0 \\
\hline 1744 & 2170 & 550 & 192 & 110 & $92.0^{*}$ & $2.7 *$ & 4.0 \\
\hline 1745 & 2245 & 565 & 183 & 90 & 84.3 & 41.5 & 3.9 \\
\hline 1746 & 2288 & 575 & 182 & 113 & 82.2 & 54.6 & 4.0 \\
\hline 1747 & 2354 & 578 & 201 & 177 & 87.9 & 52.9 & 4.1 \\
\hline 1748 & 2455 & 578 & 157 & 249 & 66.7 & 195.8 & 4.3 \\
\hline 1749 & 2524 & 579 & 158 & 73 & 64.4 & 29.7 & 4.5 \\
\hline 1750 & 2601 & 582 & 174 & 106 & 68.9 & 42.0 & 4.5 \\
\hline 1753 & 2838 & 608 & 175 & 110 & 63.0 & 40.0 & 4.7 \\
\hline 1754 & 2921 & 621 & 179 & 103 & 63.1 & 36.3 & 4.7 \\
\hline 1755 & 3051 & & 153 & & 52.4 & & \\
\hline 1756 & 3056 & 674 & 180 & 113 & 59.0 & 37.0 & 4.5 \\
\hline 1757 & 3121 & & 185 & & 60.5 & & \\
\hline 1758 & & & 190 & & 60.9 & & \\
\hline 1759 & 3150 & 752 & 167 & 130 & $53.7 *$ & $41.8 *$ & 4.2 \\
\hline 1760 & 3197 & & 203 & & 64.4 & & \\
\hline 1761 & 3236 & & 190 & & 59.4 & & \\
\hline 1762 & 3294 & 781 & 200 & 177 & 61.8 & 54.7 & 4.2 \\
\hline 1763 & 3292 & 781 & 188 & 228 & 57.1 & 69.2 & 4.2 \\
\hline 1764 & 2031 & 178 & 211 & 1614 & 64.1 & 490.3 & 11.4 \\
\hline 1765 & 1934 & 414 & 59 & 211 & 29.0 & 40.9 & 4.7 \\
\hline 1767 & 2243 & 497 & 126 & 59 & $57.5 *$ & $4.7 *$ & 4.5 \\
\hline 1802 & 1193 & & 131 & 82 & 103.9 & 65.0 & \\
\hline 1803 & 1578 & 373 & 107 & 82 & 89.7 & 68.7 & 4.2 \\
\hline
\end{tabular}

*Estimado

Tabla3: La Población femenina de Santa Rosa como porcentaje de la población total, en años seleccionados (Documentos que se indican en la nota 3 a continuación)

\begin{tabular}{|c|c|c|c|c|c|}
\hline Año & Porcentaje & Año & Porcentaje & Año & Porcentaje \\
\hline 1724 & 51.0 & 1745 & 51.8 & 1763 & 51.9 \\
\hline 1733 & 54.5 & 1746 & 49.7 & 1764 & 51.8 \\
\hline 1736 & 55.8 & 1747 & 51.7 & 1765 & 50.4 \\
\hline 1739 & 55.0 & 1753 & 51.4 & 1767 & 51.9 \\
\hline 1740 & 54.7 & 1756 & 52.0 & 1772 & 51.7 \\
\hline 1741 & 53.8 & 1759 & 51.9 & 1799 Presente & 50.6 \\
\hline 1744 & 54.3 & 1762 & 52.3 & 1799 Ausente & 23.9 \\
\hline
\end{tabular}


Tabla 4: Los matrimonios registrados en Santa Rosa y Loreto, 1756-1767 (Consulte los documentos que se indican en la nota 3 a continuación).

\begin{tabular}{|l|c|c|}
\hline Año & Matrimonios en Santa Rosa & Matrimonios en Loreto \\
\hline 1756 & 47 & 30 \\
\hline 1759 & 52 & 46 \\
\hline 1762 & 72 & 101 \\
\hline 1763 & 31 & 142 \\
\hline 1764 & 70 & 70 \\
\hline 1765 & 238 & 303 \\
\hline 1767 & 79 & 79 \\
\hline
\end{tabular}

\section{Referencias Documentales.}

Annua Enumeratio Reductionum Anni 1755, Archivo General de la Nación, Buenos Aires, Sala 9-6-10-6.

Annua Enumeratio Reductionum Anni 1757, Archivo General de la Nación, Buenos Aires, Sala 9-6-10-6.

Annua Enumeratio Reductionum Anni 1760, Archivo General de la Nación, Buenos Aires, Sala 9-6-10-6.

Carta Anua 1756-1762, Biblioteca Nacional, Archivo General de la Nación, Buenos Aires, Ms. 4421 lat.

Catalogo de la numeración annual de las Doctrinas del Río Paraná Año 1736, Archivo General de la Nación, Buenos Aires, Sala 9-6-9-7.

Catalogo de la numeración annual de las Doctrinas del Río Paraná Año 1739, Archivo General de la Nación, Buenos Aires, Sala 9-6-9-7.

Catalogo de la numeración annual de las Doctrinas del Río Paraná Año 1740, Archivo Nacional, Asunción Paraguay.

Catalogo de la numeración annual de las Doctrinas del Río Paraná Año 1750, Archivo General de la Nación, Buenos Aires, Sala 9-6-9-7.

Catalogo de la numeración annual de las Doctrinas del Río Paraná Año 1752, Archivo General de la Nación, Buenos Aires, Sala 9-6-9-7.

Catalogo de la numeración annual de las Doctrinas del Río Paraná Año 1754, Archivo General de la Nación, Buenos Aires, Sala 9-6-9-7.

Catalogo de la numeración annual de las Doctrinas del Río Paraná Año 1762, Archivo General de la Nación, Buenos Aires, Sala 9-6-9-7.

Catalogo de la numeración annual de las Doctrinas del Río Paraná Año 1763, Archivo General de la Nación, Buenos Aires, Sala 9-6-9-7.

Catalogo de la numeración annual de las Doctrinas del Río Paraná Año 1765, Archivo General de la Nación, Buenos Aires, Sala 9-6-9-7.

Difuntos de Viruelas, Archivo General de la Nación, Buenos Aires, Sala 9-6-10-6. 
Enumeratio Annua, 1733, Archivo General de la Nación, Buenos Aires, Sala 9-6-9-6.

Enumeratio Annua, 1736, Archivo General de la Nación, Buenos Aires, Sala 9-6-9-7.

Estado que manifiesta el número total de Almas de que se compone este Pueblo de Sta. Rosa del Paraguay, y de las que se hallan prófugas..., Santa Rosa, abril 17, 1799, Archivo General de la Nación, Buenos Aires, Sala 9-18-2-2.

Familias, y Almas de los 7 Pueblos de la otra banda del Uruguay, y los Pueblos en que están repartidas, 1763, 1764, y 1765, Archivo General de la Nación, Buenos Aires, Sala 9, 6-10-6.

Las Familias de los 3 Pueblos S Luis, S Juan, y Sto Ángel están repartidas en los Pueblos Siguientes, Archivo General de la Nación, Buenos Aires, Sala 9-6-10-6.

Littré Annuae Provincia Paraguarie Anno 1720, Archivum Romanum Societatis Iesu, Ciudad Vaticano.

Littré Annuae Provincia Paraguarie Anno 1735, Archivum Romanum Societatis Iesu, Ciudad Vaticano.

Muertos de la Epidemia de Viruelas este Año de 1764, Archivo General de la Nación, Buenos Aires, Sala 9-6-10-6.

Pastells, Pablo (1948), Historia de la Compañía de Jesús en la Provincia del Paraguay, 9 vols. Madrid: CSIC-Instituto Santo Toribio de Mogrovejo.

Registro de bautismos de Santa Rosa, Archivo Parroquial de Santa Rosa, Paraguay.

\section{Bibliografía}

Carbonell de Masy, S.J., Rafael (1992). Estrategias de desarrollo rural en los pueblos guaraníes, 1609-1767, Barcelona: Instituto de Cooperación Iberoamericana.

Furlong Cardiff, S.J., Guillermo (1962). Misiones y sus pueblos de Guaraníes, Buenos Aires: Tip. Editora.

Ganson, Barbara (2003). The Guarani Under Spanish Rule in the Río de la Plata, Stanford: Stanford University Press.

Garenne, Michel y Lafon, Monique (1998). “Sexist Diseases,” Perspectives in Biology and Medicine $\mathrm{n}^{\circ} 41$.

Hernández S.J., Pablo (1913). Organización social de las Doctrinas Guaraníes de la Compañía de Jesús, 2 volúmenes, Barcelona: Gustavo Gili Editor.

Jackson, Robert H. (1994). Indian Population Decline: The Missions of Northwestern New Spain, 1687-1840. Albuquerque: University of New Mexico Press.

(2004a). "Demographic Patterns in the Jesuit Missions of the Río de la Plata Region: The Case of Corpus Christi, 1622-1802," Colonial Latin American Historical Review, $\mathrm{n}^{\circ} 13$.

-- (2004b). "Una mirada a los patrones demográficos de las misiones jesuitas de Paraguay,” Fronteras de la Historia n ${ }^{\circ} 9$. 
- (2007). "The Post-Jesuit Expulsion Population of the Paraguay Missions, 1768-1803," Colonial Latin American Historical Review n ${ }^{\circ} 16$.

(2008). "The Population and Vital Rates of the Jesuit Missions of Paraguay 1700-1767,” Journal of Interdisciplinary History, no 28.

(2009). "Missions on the Frontiers of Spanish America," Journal of Religious History $\mathrm{n}^{\circ} 33$.

(2013). "The Chichimeca Frontier and the Evangelization of the Sierra Gorda, 1550-1779”, Estudios de Historia Novohispana, nº 47.

-- (2014). “Comprendiendo los efectos de las enfermedades del Viejo Mundo en los nativos americanos: la viruela en las Misiones Jesuíticas de Paraguay”, IHS. Antiguos jesuitas en Iberoamérica, V.1-n 2.

Livi-Bacci, Masimo y Maeder, Ernesto (2004). "The Missions of Paraguay: The Demography of an Experiment,” Journal of Interdisciplinary History, $\mathrm{n}^{\circ} 35$.

Lovay, Silvana (2013). "La visita de Santiago de Liniers a los pueblos de San Cosme, Santiago, Santa Rosa, San Ignacio Guazú y Santa María de Fe,” IHS Antiguos Jesuitas en Iberoamérica, V.1-n ${ }^{\circ} 1$.

Maeder, Ernesto (1996). Una Aproximación a las Misiones guaraníticas, Buenos Aires: Universidad Católica Argentina.

Page, Carlos A. (2015). La reducción jesuítica de Santa Rosa y su Capilla de Loreto, Asunción del Paraguay: Editorial. Serie: JASY KAÑY / Luna Escondida. 